\title{
Peyronie's disease after urethral swab, an unusual complication: a case report
}

\author{
This article was published in the following Dove Press journal: \\ Research and Reports in Urology \\ 3 November 2015 \\ Number of times this article has been viewed
}

\author{
Gianni Paulis ${ }^{1,2}$ \\ Davide Barletta ${ }^{3}$ \\ 'Andrology Center, Regina \\ Apostolorum Hospital, Albano Laziale, \\ Rome, Italy; ${ }^{2}$ Castelfidardo Medical \\ Team, Peyronie's Disease Care Center, \\ Rome, Italy; ${ }^{3}$ Department of Urology, \\ Andrology Center, San Matteo \\ Hospital, Pavia, Italy
}

\begin{abstract}
Urethral swabs are still currently used as a diagnostic tool when urethritis or prostatitis are suspected. Urologists are certainly aware that Peyronie's disease may occur after traumatic urethral instrumentation (catheterization, urethrocystoscopy, etc), but onset of Peyronie's disease after urethral swab for diagnostic purposes has never been reported in the literature. This paper presents the case of a patient who developed Peyronie's disease after a clumsy urethral swab insertion. It is an unusual, and to date unreported, complication which we would like to call attention to. In the case of our patient, the swab had been inserted to a greater depth than normally required and strong pressure had also been applied. During the procedure, the patient experienced severe urethral and penile pain, which was followed by urethrorrhagia, and later penile curvature. The patient was treated conservatively with good results, partly because the disease was still in its active stage and not yet stable. In the light of what we report, when ordering a urethral swab, physicians should always recommend that it be performed at testing centers that follow accurate, rigorous standards. Patients should also be informed that the test they are to undergo consists of a swab being inserted into the urethra for a short distance, not more than $2-3 \mathrm{~cm}$.
\end{abstract}

Keywords: genitourinary trauma, penile curvature, Peyronie, urethral swab

\section{Introduction}

Peyronie's disease is a chronic inflammatory condition affecting the tunica albuginea of the corpora cavernosa of the penis. Patients are males with a mean age of 53-55 years, but it must be noted that approximately $10 \%-16.9 \%$ are younger than 40 years of age. ${ }^{1,2}$ There are, furthermore, rare cases of adolescents suffering from this disease. ${ }^{3}$ Contrary to common belief, it is not a rare disease: its incidence varies between studies from $3.2 \%$ to $13 \% .^{4-6}$

The disease is often associated with the following risk factors: penile trauma, congenital penile curvature, all conditions associated with increased oxidative stress (eg, chronic inflammatory conditions), diabetes mellitus, high blood pressure, obesity, androgen deficiency, cigarette smoke, decreased penile rigidity, and recent radical prostatectomy (incidence $=15.9 \%)^{7}$

The exact etiology of Peyronie's disease has not yet been determined, but trauma has generally been recognized as the fundamental pathogenetic mechanism underlying the disease.$^{8-10}$ Trauma or repeated microtrauma, prevalently to the erect penis, in genetically predisposed patients is believed to be the trigger of the inflammatory mechanism that leads to a deposition of fibrin and progressive loss of the elastic fibers that make up the tunica albuginea. However, studies have found both an immunological and a genetic
Correspondence: Gianni Paulis Castefidardo Medical Team (SMS), Via Castefidardo 34, 00185 Rome, Italy Email paulisg@libero.it 
component in patients with Peyronie's disease. ${ }^{11,12}$ A very recent study found a highly statistically significant association between Peyronie's disease and autoimmune diseases (odds ratio: $4.90 ; P<0.01) .{ }^{13}$ Another study showed that the WNT2 locus is involved in genetic predisposition to both Dupuytren's and Peyronie's diseases. ${ }^{14}$

Peyronie's disease is characterized from the beginning by an inflammatory area (plaque) of the tunica albuginea of the corpora cavernosa, where fibroblasts and myofibroblasts produce an excessive amount of collagen. ${ }^{15}$ As penile plaque progressively builds up, it causes a loss of elasticity in the affected region. This frequently results in morphological changes in the penis: curvature, divots, hourglass deformity, and shortening. Although these changes may apparently be absent, as the disease progresses they can cause a degree of curvature and shortening of the penis that are incompatible with complete sexual intercourse.

Medical therapy is indicated until the disease has completely stabilized; considering the long duration (3-5 years) of the natural history of the disease, most patients who come to our attention require a medical approach.

When the penile curvature is such as to severely hinder penetration, surgical therapy is indicated.

Anatomical studies show that the tunica albuginea of the corpora cavernosa is made up of two layers of collagen, a longitudinally oriented outer layer and a circularly oriented inner layer. The longitudinal layer is absent ventrally, over the urethra, between the 5 and 7 o'clock positions. ${ }^{16,17}$ This creates a ventral groove that allows the corpus spongiosum of the urethra to expand without narrowing, avoiding a possible obstacle to ejaculation. ${ }^{16,17}$ This ventral groove represents an area of lesser resistance, a "vulnerable" area where perforations of the corpora cavernosa may occur, for example, during penile prosthesis surgery. Furthermore, this is where penile prostheses can extrude after this type of surgery, as a postoperative or late complication. Based on these anatomical considerations, it is clear that any traumatic urethral manipulation at this site can pose a risk (catheterization, erroneous insertion of endoscopic tools such as cystoscopes and urethroscopes, etc).

The aim of this paper is to alert specialists in this field to the possibility of Peyronie's disease occurring after traumatic urethral manipulation with a urethral swab used for diagnostic purposes. We define "urethral swab" as a medical procedure that consists of inserting a small cotton swab into the urethra. The correct procedure calls for insertion of the swab into the urethra to a maximum depth of $2-3 \mathrm{~cm}(0.8-1.2$ inches) to collect a specimen and verify the presence of infection. ${ }^{18}$
In this article, we report a case of Peyronie's disease which occurred in a 25-year-old male after he underwent a urethral swab test.

\section{Clinical case}

A 25-year-old patient presented to our clinic (Peyronie's Disease Care Center, Rome) in June 2014, complaining of penile pain and recent onset of penile curvature. Approximately 9 months before, due to prostate problems, he had been advised by the urologist to undergo culturing with a urethral swab to collect a specimen of urethral secretions. Having gone to a lab in his town, he reported that the health care professional had inserted a cotton-tipped swab very deeply into the penile urethra (approximately 9-10 cm), causing him severe pain in the urethra at the base of the penis, with subsequent occurrence of urethrorrhagia and initial gross hematuria; the latter symptoms lasted for approximately 3 days and gradually subsided. However, the patient reported that he continued to experience localized pain and burning with urination in the following 3 months, after which he noticed penile curvature (to the left and downward), which gradually increased until it reached $60^{\circ}$ downward and $30^{\circ}$ to the left (see Figure 1) at the time of our observation.

At the time of our first observation, dynamic penile ultrasound performed approximately 9 months after the trauma showed a hyperechoic area approximately $1.76 \mathrm{~cm}$ long near the proximal third of the penis (see Figure 2).

Apart from the temporary urethral pain and urethrorrhagia, the patient did not develop any secondary urethral stricture.

After the informed consent process, the patient underwent multimodal (antioxidant) medical therapy. The first ultrasound checkup after approximately 6 months showed a $45.5 \%$ reduction in the volume of plaque. The pain

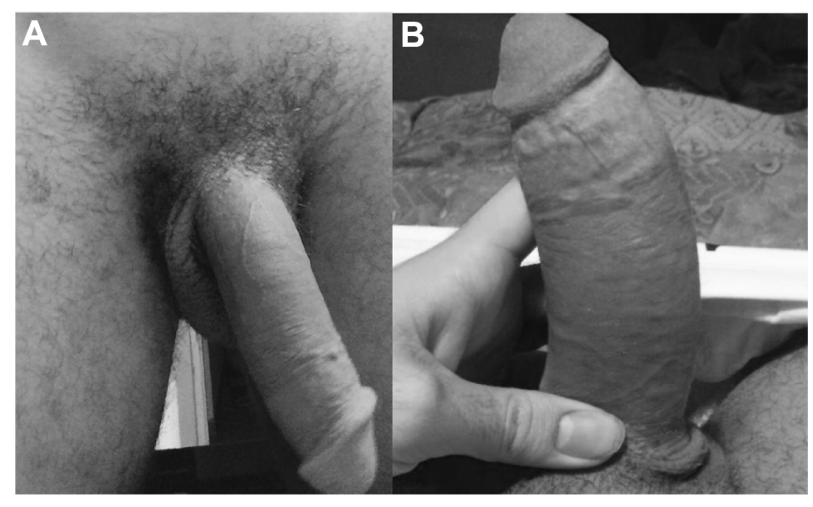

Figure I Photographs during penile erection. Notes: (A) frontal pose. (B) pose from above. 


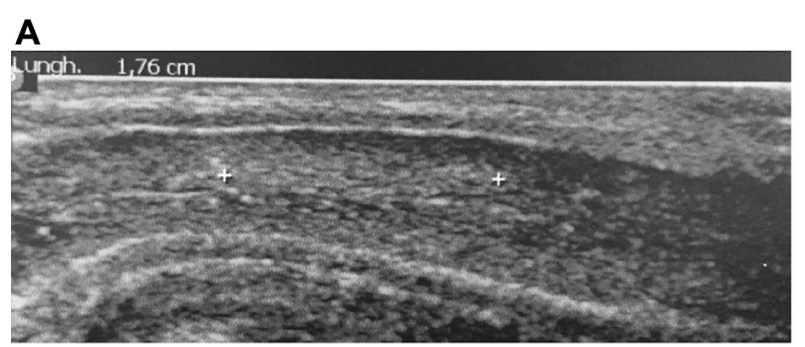

B

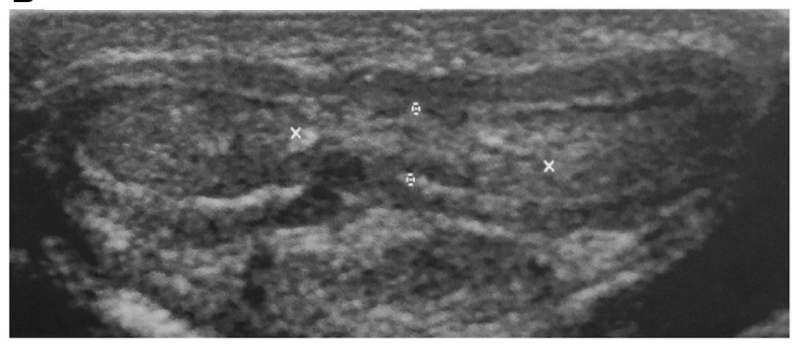

Figure 2 Penile ultrasound images.

Notes: (A) Longitudinal section image. (B) Transverse section image.

decreased from a score of 9 to a score of 2 on a visual analog scale, and the left-side curvature diminished from $30^{\circ}$ to $25^{\circ}$, while the downward bend decreased from $60^{\circ}$ to $30^{\circ}$. The patient gave written informed consent for publication of his clinical case, including photographs of his penis and ultrasound images. This case report did not need the approval from an ethics committee.

\section{Discussion}

Urethral swabs, despite their causing discomfort and pain in patients, are still recommended by many doctors to diagnose urethral and prostate infections. ${ }^{19}$

The possibility that Peyronie's disease may develop after traumatic urethral instrumentation (catheterization, urethrocystoscopy, transurethral resection of the prostate, etc) is assuredly known to urologists. Nevertheless, only two studies in the literature directly mention urethral manipulations as risk factors for Peyronie's disease. ${ }^{20,21}$ It must be noted, furthermore, that in these two articles, urethral swabs are not mentioned in the given list of urethral manipulations. Moreover, even though several cases of complications following self-insertion of extraneous bodies in the urethra are mentioned in the literature, in none of these has subsequent onset of Peyronie's disease been reported. ${ }^{22-24}$ In particular, one article mentions a case of a self-insertion of a cottontipped swab, but, even in this case, this did not result in the development of Peyronie's disease or any urethral stricture. ${ }^{25}$ The same paper reports that urethral stricture appeared in only two patients (out of 17 in total) and only after repeated urethral manipulations; in any case, urethral swabs were never the cause. ${ }^{25}$ This makes it easier to understand why no urethral stricture occurred in our case.

We therefore believe that urethral swabs may cause Peyronie's disease only in the case of urethral manipulation performed clumsily, in depth, and with strong pressure applied toward the corpora cavernosa (ventral direction). In our case, the swab was inserted at a depth greater than normally required, and, most importantly, forceful pressure was applied. This caused severe urethral and penile pain during the procedure and subsequent urethrorrhagia.

\section{Conclusion}

Since urethral swab tests are commonly used in urology, they should be performed correctly.

It is important for urologists to be aware that, if clumsily performed, urethral swab insertion may cause a lesion to the corpora cavernosa with subsequent development of Peyronie's disease. When referring a patient for a urethral swab, physicians should advise patients to always select a testing center that follows accurate, rigorous standards. Patients should also always be informed that the test they are to undergo consists of a cotton swab being inserted into the urethra to a short distance (not more than 2-3 cm). Although, at present, a nucleic acid amplification test is also frequently used on the first-voided urine specimens, nevertheless, this noninvasive test is limited for the detection of sexually transmitted infections. ${ }^{26-29}$ In order to avoid urethral manipulations and their possible iatrogenic damages, we think, like other authors, that the culture test of first-voided urine specimens should always be preferred for the detection of prostatic and urethral bacterial infections. ${ }^{30,31}$ Swabs for microbial culture could be used too, but only to catch the first urine.

\section{Disclosure}

The authors report no conflicts of interest in this work.

\section{References}

1. Deveci S, Hopps CV, O’Brien K, Parker M, Guhring P, Mulhall JP. Defining the clinical characteristics of Peyronie's disease in young men. J Sex Med. 2007;4(2):485-490.

2. Paulis G, Cavallini G, Barletta D, Turchi P, Vitarelli A, Fabiani A. Clinical and epidemiological characteristics of young patients with Peyronie's disease: a retrospective study. Res Rep Urol. 2015;7:107-111.

3. Tal R, Hall MS, Alex B, Choi J, Mulhall JP. Peyronie's disease in teenagers. J Sex Med. 2012;9(1):302-308.

4. Schwarzer U, Sommer F, Klotz T, Braun M, Reifenrath B, Engelmann U. The prevalence of Peyronie's disease: results of a large survey. BJU Int. 2001;88(7):727-730.

5. Mulhall JP, Creech SD, Boorjian SA, et al. Subjective and objective analysis of the prevalence of Peyronie's disease in a population of men presenting for prostate cancer screening. J Urol. 2004;171(6 Pt 1): $2350-2353$. 
6. Dibenedetti DB, Nguyen D, Zografos L, Ziemiecki R, Zhou X. A population-based study of Peyronie's disease: prevalence and treatment patterns in the United States. Adv Urol. 2011;2011:282503.

7. Tal R, Heck M, Teloken P, Siegrist T, Nelson CJ, Mulhall JP. Peyronie's disease following radical prostatectomy: incidence and predictors. J Sex Med. 2010;7(3):1254-1261.

8. Devine CJ Jr, Somers KD, Jordan GH, Schlossberg SM. Proposal: trauma as the cause of the Peyronie's lesion. J Urol. 1997;157(1): 285-290.

9. Jarow JP, Lowe FC. Penile trauma: an etiologic factor in Peyronie's disease and erectile dysfunction. J Urol. 1997;158(4):1388-1390.

10. Zargooshi J. Trauma as the cause of Peyronie's disease: penile fracture as a model of trauma. J Urol. 2004;172(1):186-188.

11. Schiavino D, Sasso F, Nucera E, et al. Immunologic findings in Peyronie's disease: a controlled study. Urology. 1997;50(5):764-768.

12. Stewart S, Malto M, Sandberg L, Colburn KK. Increased serum levels of anti-elastin antibodies in patients with Peyronie's disease. J Urol. 1994;152(1):105-106.

13. Ventimiglia E, Capogrosso P, Colicchia M, et al. Peyronie's disease and autoimmunity - a real-life clinical study and comprehensive review. J Sex Med. 2015;12(4):1062-1069.

14. Dolmans GH, Werker PM, de Jong IJ, Nijman RJ; LifeLines Cohort Study, Wijmenga C, Ophoff RA. WNT2 locus is involved in genetic susceptibility of Peyronie's disease. J Sex Med. 2012;9(5): 1430-1434.

15. Gonzalez-Cadavid NF. Mechanisms of penile fibrosis. $J$ Sex Med. 2009;6 Suppl 3:353-362.

16. Brock G, Hsu GL, Nunes L, von Heyden B, Lue TF. The anatomy of the tunica albuginea in the normal penis and Peyronie's disease. J Urol. 1997;157(1):276-281.

17. Hsu GL, Hsieh CH, Wen HS, et al. Anatomy of the human penis: the relationship of the architecture between skeletal and smooth muscles. $J$ Androl. 2004;25(3):426-431.

18. Guirguis-Blake J, Krist AH, Woolf SH. Laboratory screening tests. In: Woolf SH, Jonas S, Kaplan-Liss E, editors. Health Promotion and Disease Prevention in Clinical Practice. 2nd ed. Philadelphia: Lippincott Williams \& Wilkins; 2007:89-128.

19. Apoola A, Herrero-Diaz M, FitzHugh E, Rajakumar R, Fakis A, Oakden J. A randomised controlled trial to assess pain with urethral swabs. Sex Transm Infect. 2011;87(2):110-113.
20. Bjekic MD, Vlajinac HD, Sipetic SB, Marinkovic JM. Risk factors for Peyronie's disease: a case-control study. BJU Int. 2006;97(3): 570-574.

21. Carrieri MP, Serraino D, Palmiotto F, Nucci G, Sasso F. A case-control study on risk factors for Peyronie's disease. J Clin Epidemiol. 1998; 51(6):511-515.

22. Osca JM, Broseta E, Server G, Ruiz JL, Gallego J, Jimenez-Cruz JF. Unusual foreign bodies in the urethra and bladder. $\mathrm{Br} J$ Urol. 1991;68(5):510-512.

23. Aliabadi H, Cass AS, Gleich P, Johnson CF. Self-inflicted foreign bodies involving lower urinary tract and male genitals. Urology. 1985;26(1):12-16.

24. Kenney RD. Adolescent males who insert genitourinary foreign bodies: is psychiatric referral required? Urology. 1988;32(2):127-129.

25. Rahman NU, Elliott SP, McAninch JW. Self-inflicted male urethral foreign body insertion: endoscopic management and complications. BJU Int. 2004;94(7):1051-1053.

26. Cook RL, Hutchison SL, Østergaard L, Braithwaite RS, Ness RB. Systematic review: noninvasive testing for Chlamydia trachomatis and Neisseria gonorrhoeae. Ann Intern Med. 2005;142(11):914-925.

27. Wisniewski CA, White JA, Michel CE, et al. Optimal method of collection of first-void urine for diagnosis of Chlamydia trachomatis infection in men. J Clin Microbiol. 2008;46(4):1466-1469.

28. Hamasuna R, Kawai S, Ando Y, et al. [Usefulness of real-time PCR in detecting Chlamydia trachomatis and Neisseria gonorrhoeae in endocervical swabs and first-voided urine specimens]. Kansenshogaku Zasshi. 2013;87(5 Suppl 8):17-23. Japanese.

29. McKechnie ML, Kong F, Gilbert GL. Simultaneous direct identification of genital microorganisms in voided urine using multiplex PCR-based reverse line blot assays. Methods Mol Biol. 2013;943:229-245.

30. Magri V, Cariani L, Bonamore R, Restelli A, Garlaschi MC, Trinchieri A. Microscopic and microbiological findings for evaluation of chronic prostatitis. Arch Ital Urol Androl. 2005;77(2):135-138.

31. Sugunendran H, Birley HD, Mallinson H, Abbott M, Tong CY. Comparison of urine, first and second endourethral swabs for PCR based detection of genital Chlamydia trachomatis infection in male patients. Sex Transm Infect. 2001;77(6):423-426.
Research and Reports in Urology

\section{Publish your work in this journal}

Research and Reports in Urology is an international, peer-reviewed, open access journal publishing original research, reports, editorials, reviews and commentaries on all aspects of adult and pediatric urology in the clinic and laboratory including the following topics: Pathology, pathophysiology of urological disease; Investigation and treatment of

\section{Dovepress}

urological disease; Pharmacology of drugs used for the treatment of urological disease. The manuscript management system is completely online and includes a very quick and fair peer-review system, which is all easy to use. Visit http://www.dovepress.com/testimonials.php to read real quotes from published authors. 